\title{
Burden of motorcycle-related injury in Malaysia
}

Nik Hisamuddin NA Rahman ${ }^{1 *}$, Kamarul A Baharuddin ${ }^{1}$ and Syarifah Mastura S Mohamad²

\begin{abstract}
Background: Road traffic injury (RTI) contributes to major morbidity and mortality in both developed and developing countries. Most of the injuries are caused by road-related injuries that specifically relate to motorcycle crash. We attempted to conduct a short survey to determine the magnitude of burden related to motorcycle-related RTIs in Malaysia. We hypothesize that motorcycle-related RTI in Malaysia contributes significantly to the health burden in the country.

Methods: The cross-sectional survey involves data searching related to RTI in Malaysia from the relevant agencies such as the Ministry of Health Malaysia, Royal Police Force, and Malaysia Institute of Road Safety Research (MIROS) through their official websites and PubMed search. The three agencies are well established and recognized by the Malaysian government in dealing with data collection for the injury nationwide. The primary aim is to determine the prevalence of motorcycle-related RTI, and secondary outcomes are the overall mortality and the contributing factors.
\end{abstract}

Results: Of the cause of trauma, $80 \%$ is due to RTI, and the most vulnerable road users such as pedestrians and motorcyclists are affected the most. Of all RTI, $70 \%$ is contributed by the motorcycle crash, and there are a significant number of deaths for both rider and pillion rider of the motorcycle than for other types of vehicles. Human error is the main reason to be blamed, specifically the attitude of the riders on the road.

Conclusions: Trauma is one of the common reasons for death and hospitalization in Malaysia. Motorcycle-related RTI in Malaysia contributes significantly to the health burden in Malaysia. The Malaysian government and non-government agencies have worked together seriously in implementing a preventive measure to reduce the incidence and aftermath of motorcycle-related RTI. However, data is still lacking, and every effort is made to increase the amount of research in the field.

Strengths of the article are as follows:

- Latest alarming data on motorcycle-related injuries in the developing country.

- The data is collected from multi-agencies recognized by ministries in the country.

- Very limited publication specifically on motorcycle-related injuries is available.

Limitations of the article are as follows:

- The data is only from one country.

- The statistical data is gathered from a variety of sources, i.e., relevant agencies and authorities and website of the involved ministries.

Keywords: Injury; Road safety; Motorcycle; Trauma

\footnotetext{
*Correspondence: nhliza@hotmail.com

'School of Medical Sciences, USM, Kota Bharu 16150, Malaysia

Full list of author information is available at the end of the article
} 


\section{Background}

Road traffic injury (RTI) contributes to major morbidity and mortality in both developed and developing countries. Malaysia spans over $330,289 \mathrm{~km}^{2}$. Its 29.33 million population in 2012 comprises of $51 \%$ male and $49 \%$ female. The majority are Malays and indigenous Malay ethnic group (66.1\%). The majority of the population is between the age of 15 and 64 years $(68.3 \%)$. The annual population growth rate is $1.3 \%$. This yields a population density of 85 per $\mathrm{km}^{2}$. The life expectancies in Malaysia for males and females were 72 and 76 years old, respectively [1]. Malaysia is categorized as a middle-income country, with approximately US\$13,740 per capita gross domestic product (GDP). However, the government spends only $7.7 \%$ of its annual budget on health care (US\$ 6.33 billion) most of which is utilized for the operation of the health system ( $89 \%)$. The remainder is used for the development projects nationwide [2]. In Malaysia, injury is one of the top six leading causes of hospital admission and deaths after ischemic heart disease, cerebrovascular disease, septicemia, neoplastic disease, and pneumonia (Table 1) [3]. Most of the injuries are caused by road-related injuries specifically related to motorcycle crash. We attempted to conduct a short survey to determine the magnitude of burden related to motorcycle-related RTI in Malaysia.

\section{Methods}

The cross-sectional survey involves data searching related to RTI in Malaysia from the relevant agencies such as the Ministry of Health Malaysia, Royal Police Force, and Malaysia Institute of Road Safety Research (MIROS) through their official websites and PubMed search. The primary aim is to determine the prevalence of the motorcycle-related RTI, and secondary outcomes are the overall mortality and the contributing factors.

Table $1 \mathrm{MOH}$ statistics on the top 10 causes of hospital admission in Malaysia

\begin{tabular}{lll}
\hline Ten principal causes of hospitalization in Malaysian hospitals, 2012 \\
\hline 1. & Pregnancy, childbirth, and the puerperium & $27.32 \%$ \\
2. & Diseases of the respiratory system & $11.02 \%$ \\
3 & $\begin{array}{l}\text { Injury, poisoning, and certain other consequences of } \\
\text { external causes }\end{array}$ & $8.22 \%$ \\
4. & Diseases of the circulatory system & $7.55 \%$ \\
5. & Certain conditions originating in the perinatal period & $7.55 \%$ \\
6. & Certain infectious and parasitic diseases & $6.82 \%$ \\
7. Diseases of the digestive system & $4.88 \%$ \\
8. Diseases of the genitourinary system & $4.48 \%$ \\
9. & Factors influencing health status and contact with health & $3.64 \%$ \\
10. & Nervices & $3.34 \%$ \\
\hline
\end{tabular}

The fatality cases include those who died immediately at the scene and late death in hospitals after sustaining motorcycle-related RTI.

This article does not require ethical approval because it is a brief review report article and does not involve data collection from patients.

\section{Results}

Road traffic accidents (RTA) contribute to most of the injury cases in Malaysia. There were over 400,000 reported cases of RTA according to the Malaysian Police Force statistics year 2011 (Table 2).

Statistically, there is an average 19 deaths due to RTA daily, a phenomenon that is very alarming. According to the World Health Organization (WHO) ranking, Malaysia is at the 20th place in the world for death ranking due to RTA. The latest WHO report shows that the death rate in Malaysia due to RTA is 34.5 for every 100,000 population [4]. The majority of the RTI victims involve the most vulnerable group of road users namely pedestrians, motorcyclists, and their pillion riders. Motorcycles are a relatively cheap and reliable mode of transportation in Malaysia. In the year 1990, the number of registered cars and motorcycles was 1,811,141 and 3,035,930, respectively. In 2007, the number yet increases to $7,419,643$ for cars and $7,943,364$ for motorcycles [5]. This increasing number of vehicles affects the density of vehicles per road and thus the number of mishaps at a particular area (Table 3).

Of all RTA victims in 2012, approximately $70 \%$ involved motorcyclists. Motorcyclist-related fatalities accounted for $60 \%$ of all road fatalities. Interesting facts are that most of these victims were young adolescents, and many of them did not hold any valid driving license [6]. In 2008, 428,475 cars and 111,958 motorcycles were reported to be involved in accidents. The total fatalities in the same year were 6287. Of those who died, $58.7 \%$ involved the motorcycle

Table 2 Total casualties and damages caused by RTA in Malaysia, 2002-2011

\begin{tabular}{llllll}
\hline Year & Total number of & \multicolumn{3}{l}{ Casualties } & Total \\
\cline { 3 - 5 } & accidents & Death & Serious & Minor & \\
\hline 2002 & 279,237 & 5,891 & 8,425 & 35,236 & 49,552 \\
2003 & 298,653 & 6,286 & 9,040 & 37,415 & 52,741 \\
2004 & 326,817 & 6,228 & 9,229 & 38,631 & 54,088 \\
2005 & 328,264 & 6,200 & 9,397 & 31,429 & 47,026 \\
2006 & 339,252 & 6,287 & 9,254 & 19,884 & 35,425 \\
2007 & 363,319 & 6,282 & 9,273 & 18,444 & 33,999 \\
2008 & 372,990 & 6,527 & 8,866 & 16,901 & 32,294 \\
2009 & 397,330 & 6,745 & 8,849 & 15,823 & 31,417 \\
2010 & 414,421 & 6,872 & 7,781 & 13,616 & 28,269 \\
2011 & 449,040 & 6,877 & 6,328 & 12,365 & 25,570 \\
\hline
\end{tabular}

Source: Royal Malaysian Police 
Table 3 The total number of vehicles involved in RTA in Malaysia, 2002-2011

\begin{tabular}{lllllllllll}
\hline Year & Motorcycle & Motorcar & Van & Bus & Lorry & Four-wheel drive & Taxi & Bicycle & Others & Total \\
\hline 2002 & 86,779 & 320,649 & 19,077 & 9,256 & 37,794 & 14,783 & 6,187 & 3,278 & 10,043 & 507,843 \\
2003 & 95,545 & 351,832 & 20,277 & 9,673 & 42,753 & 16,429 & 6,632 & 2,993 & 9,500 & 555,634 \\
2004 & 99,227 & 388,589 & 20,086 & 9,265 & 45,420 & 18,306 & 7,111 & 2,963 & 11,186 & 602,153 \\
2005 & 97,072 & 376,061 & 19,085 & 8,594 & 42,062 & 19,106 & 7,043 & 2,751 & 9,362 & 581,136 \\
2006 & 104,107 & 411,444 & 20,428 & 9,700 & 44,767 & 20,885 & 7,751 & 2,834 & 12,266 & 634,182 \\
2007 & 111,765 & 426,941 & 21,109 & 10,285 & 47,696 & 21,823 & 8,809 & 2,690 & 14,909 & 6666,027 \\
2008 & 111,819 & 435,665 & 20,392 & 9,356 & 48,250 & 22,793 & 8,769 & 2,463 & 11,571 & 671,078 \\
2009 & 113,962 & 472,307 & 19,220 & 9,380 & 46,724 & 23,581 & 8,669 & 2,486 & 9,294 & 705,623 \\
2010 & 120,156 & 511,861 & 18,788 & 9,580 & 50,438 & 25,777 & 9,899 & 2,178 & 11,756 & 760,433 \\
2011 & 129,017 & 546,702 & 17,916 & 9,986 & 53,078 & 30,828 & 11,197 & 2,033 & 16,394 & 817,151 \\
\hline
\end{tabular}

Source: Royal Malaysian Police

riders and pillions. There is a significant number of deaths combined from both rider and pillion rider of motorcycles than from any other type of vehicles. In terms of admission to hospitals in Malaysia, motorcycle-related injuries are the leading cause of admission (79.9 \%) followed by motorcars (10.7\%) and others $9.4 \%$ [7]. This is further strengthened by the Malaysian national trauma database findings which reported that $64.9 \%$ of the trauma is due to motorcycle [8]. A similar trend of motorcyclist contribution to the RTI statistics is observed in other countries in the Southeast Asia (SEA) region (Table 4).

\section{Discussion}

Motorcyclists are particularly vulnerable to injury, as they do not have the steel car frame to absorb the transmitted forces imparted during a collision. There is a massive amount energy transferred to the motorcyclists upon impact, and there are three possible mechanisms by which a motorcyclist may be injured [9]. The first would be by frontal impact or ejection that occurs when the part of the motorcycle is abruptly stopped upon impact while the rest of it, together with the rider, continues to move. The axle acts as the center of gravity which tips the motorcycle forward and the rider would go over the handlebars. The impact of the head, thorax, or abdomen onto the handlebars may result in blunt abdominal injuries as well as traumatic rupture of the abdominal wall. The femurs may also be fractured if the rider's feet remain strapped onto the footrests, which result in direct impact of the femurs onto the handlebars. The second mechanism is lateral impact or ejection, which may result in open or closed fractures of the extremities of the impacted side. As the rider lands, secondary injuries may then follow. The third mechanism is when a motorcyclist attempts to slow the motorcycle down from the impending impact by turning it sideways $\left(90^{\circ}\right)$ and dropping it to the ground. The "down" leg is at risk for significant soft tissue injuries and fractures. A short survey was conducted in 2012 among all the motorcycle-related RTI in two tertiary centers in Kelantan,

Table 4 Deaths by type of road users in various regions 2012

\begin{tabular}{|c|c|c|c|c|c|c|c|c|}
\hline \multirow[t]{2}{*}{ No } & \multirow{2}{*}{$\begin{array}{l}\text { ASEAN } \\
\text { countries }\end{array}$} & \multirow[t]{2}{*}{ Population } & \multicolumn{2}{|c|}{ Registered motorcycle (2012) } & \multicolumn{2}{|c|}{ Reported fatalities (2012) } & \multirow{2}{*}{$\begin{array}{l}\text { Road fatalities } \\
\text { per } 100,000 \\
\text { population }\end{array}$} & \multirow{2}{*}{$\begin{array}{l}\text { Motorcycle fatalities } \\
\text { per } 10,000 \text { registerec } \\
\text { motorcycles }\end{array}$} \\
\hline & & & Total (million) & (\%) & Total & (\%) & & \\
\hline 1 & Brunei & 390,056 & 0.01 & 4 & 54 & 11 & 13.8 & 4.9 \\
\hline 2 & Singapore & $4,436,281$ & 0.14 & 17 & 214 & 48 & 4.8 & $7.1(3)$ \\
\hline 3 & Lao P.D.R. & $5,859,393$ & 0.51 & 79 & 608 & 80 & 10.4 & $9.6(2)$ \\
\hline 4 & Cambodia & $14,443,679$ & 0.13 & 84 & 1545 & 63 & 10.7 & $75.1(1)$ \\
\hline 5 & Malaysia & $26,571,879$ & 7.91 & 47 & 6282 & 58 & $23.6(1)$ & 4.6 \\
\hline 6 & Myanmar & $48,798,212$ & 0.68 & 65 & 1638 & 10 & 3.4 & 2.4 \\
\hline 7 & Thailand & $63,883,662$ & 16.14 & 63 & 12,493 & 70 & $19.6(3)$ & 5.4 \\
\hline 8 & Vietnam & $87,375,196$ & 21.78 & 95 & 12,800 & 80 & $14.6(3)$ & 4.7 \\
\hline 9 & Philippines & $87,375,196$ & 2.65 & 48 & 1185 & 37 & 1.3 & 1.7 \\
\hline \multirow[t]{2}{*}{10} & Indonesia & $231,626,978$ & 46.22 & 73 & 16,548 & 61 & 7.1 & 2.2 \\
\hline & Total & $571,345,453$ & 96.17 & 58 & 53,366 & 52 & - & - \\
\hline
\end{tabular}


Malaysia (Dr Aehtoosham Suleman, Type of injury presentation of traumatic motorcyclists at the emergency department in Malaysia, unpublished dissertation 2012). The investigators noted that the most commonly injured body region was the extremity that occurred in $80.0 \%$ of the study population. A large number of subjects sustained lower extremity injury (82\%) as compared to upper extremity injury (65\%), and the commonest injury pattern among these subjects were superficial wounds (65.3\%) followed by fractures $(16.3 \%)$. A similar trend is noted with injuries involving the upper extremities. The third most common injury among the motorcyclists was head injury. This ranged from superficial wounds to intracranial injury. The above finding is also observed by Pang et.al in their study on 226 non-fatal motorcyclists in Malaysia. In their study, it was reported that limb injuries outnumbered that of head, thorax, and abdomen and ranked the highest for the indication of hospitalizations among the study population (Table 5) [10]. In another study conducted in Penang, Malaysia, 140 RTA fatality cases were identified in 2007 that underwent postmortem at the forensic department of a general hospital. Of the victims who died before reaching hospital, $57 \%$ were among the motorcyclists. Of those who died, $92 \%$ sustained severe traumatic brain injury. The average AIS score for these victims was 6 (Dr Noor Azleen Ayop, Pattern of injury and preventability of pre hospital death among motorcyclists, unpublished dissertation 2012). However, further data collection nationwide is required to strengthen the finding of this survey. Unfortunately, we found that there is no uniform injury severity recording carried out among all the agencies. The police force subdivided the injury into very generic groupings namely mild, moderate, severe, and death. The only reliable clinical severity scoring is available from hospital data.

\section{Preventive efforts and research}

There are many ways to tackle this serious issue, one of which is the implementation of preventive and road traffic safety programs. Malaysia has also experienced significant change in ways to tackle road safety. Few important organizations start to integrate and work on the same issue in promoting road safety. Those include the Malaysian Police

Table 5 Pattern of injuries sustained by motorcyclists in 2012 in ED of two tertiary centers

\begin{tabular}{ll}
\hline AlS body regions & Percentage (\%) \\
\hline Head and neck & $31.7 \%$ \\
Face & $13.3 \%$ \\
Thorax & $5.0 \%$ \\
Abdomen & $5.0 \%$ \\
Extremities & $80 \%$ \\
External & $35 \%$ \\
\hline
\end{tabular}

Force (PDRM), Ministry of Transportation, Malaysian Institute of Research on Road Safety (MIROS), Department of Road Safety (JKJR), Department of Road and Transportation (JPJ), Ministry of Work, and Ministry of Health [11, 12].

Despite a lot of advancement in the modern engineering of the motorcycle, man has failed to put effective protective equipment and measures to protect the rider in the motorcycle itself. The initiative of any protection is concentrated on the rider himself rather than on the motorcycle. Thus, the rider needs to utilize protective equipments such as helmet, leather protective gears, boots and gloves, and conspicuous clothing. An essential checking of the brake light and wheel pressure besides keeping the front light switch on all the time may ensure further protection for the rider [13]. Legislation in Malaysia mandates the rider to switch on the light at daylight in order to make the rider more visible and reduce fatalities among motorcycle users [14, 15]. In Malaysia, wearing a crash helmet or a safety helmet is compulsory and mandatory by law. The helmet has its own standard for its manufacturing and its safety regulation, and in Malaysia, the bodies that ensure helmets safety is the Standards and Industrial Research Institute of Malaysia (SIRIM) [16].

A preventive measure requires considerable amount of data to elicit the current problem. Data obtained from robust studies can be used to create preventive measures and hence reduces the incidence of motorcycle-related RTI. Unfortunately, due to the limited number of prospective studies conducted in Malaysia and the lack of an integrated sustainable injury registry, neither the accurate morbidity nor the mortality of road-related motorcycle injuries has been recorded nationally. Ambak et al. conducted a cross-sectional study in Selangor, Malaysia, in 2011 to examine the percentage of compliance rate regarding helmet use and to identify its characteristics [17]. The observations among 1150 motorcyclists show that only $46.6 \%$ used helmets properly, $10.6 \%$ untied helmet, and $42.8 \%$ did not wear a helmet. The percentage of improper helmet usage in the locations of study was considered high, and it seems those helmet initiative programs are insufficient to overcome the problem. Therefore, there is a serious need to introduce a new mechanism or method that can be utilized to incorporate behavior adaptation toward safety concern among motorcycle users. In 2006, Law et al. conducted an interesting cross-sectional analysis among motorcyclists who are labelled as red light runners in Kuala Lumpur, Malaysia [18]. Interestingly, they found that most of the red light running violations occurred at the signalized intersections with highmotorcycle volume, shorter change interval time, shorter amber time, and longer cycle length. The findings can be used to evaluate the effectiveness of specific countermeasures, such as providing a longer change interval time and 
amber time, shorter cycle length, less number of signal phase, or all of them, for different traffic volumes at signalized intersections.

In 2005, a group of researchers from MIROS analyzed all motorcyclists injured who sustained cervical spine injuries in Kuala Lumpur [19]. The types of injuries sustained were acquired from medical reports. Information on the crash scene and crash mode was obtained from police reports, and interview sessions were arranged with the motorcyclists involved in the crash. Generally, a high count was noted for injuries to the lower cervical vertebrae, especially at vertebrae $\mathrm{C} 5$, intervertebral $\mathrm{C} 5$ - $\mathrm{C} 6$, and vertebrae C6. The upper cervical spine was observed to have a high frequency of injury at $\mathrm{C} 2$, especially the odontoid process. Neck flexion and extension movements are the most frequent neck injury mechanisms, especially in frontal- and rear-end-impacted motorcycles. This has proven that the mechanism of impact during the crash greatly influenced the clinical finding, and every paramedic and doctor involved in treating the victims should be made aware of the biomechanics of the injury so that they do not miss the serious injury.

There are many more ongoing researches in the same field such as the geo-mapping of the RTA, the development of the electronic road traffic injury surveillance system, and the biomechanics of injury. The research effort must involve multi-agencies, and grant support from the government must be made available continuously for the sustainable preventive projects in the future. Another area that requires more attention by the law maker is the development of a sustainable and funded nationwide data collection system such as a trauma registry. At present, unfortunately, this database system is not available nationwide but more of the regional collection which is either a manually or electronically hospital-based system. However, the police force has established a nationwide and centralized data collection on all motor vehicle crashes that are reported to them. The dataset includes the prehospital data, mechanism of crashes, severity of injury (based on body parts injured), and clinical outcome. Effort has been made to integrate data collection between agencies such as hospitals, MIROS, and the police force which has a uniform dataset definition. Even though the data mentioned above came from various sources, these published data represent prevalence among population of Malaysia and can be considered accurate enough since they were extracted from established and recognized agencies such as MIROS, the Ministry of Health, and the Royal Police Force of Malaysia. Unfortunately, we do not have the exact figure on the economic impact of trauma care on the RTI victims. This is probably another aspect that can be looked upon seriously by the government in tackling the burden of motorcyclerelated injury holistically.

\section{Limitations}

The survey obtained the data mainly from official websites and previous publication through PubMed. There is a tendency for missing data of the actual incidence of the motorcycle-related RTI and the underreporting of the factors contributing to the crash. The data is only up to the year 2012. However, the data published is from reliable and well-maintained sources and still reflects the present situation in the country.

\section{Conclusions}

Trauma is one of the common reasons for death and hospitalization in Malaysia. Motorcycle-related RTI in Malaysia contributes significantly to the health burden in Malaysia. The Malaysian government and non-government agencies have worked together and seriously in implementing the preventive measure to reduce the incidence and the aftermath of the motorcycle-related RTI. However, data is still lacking, and every suitable effort is taken to increase the amount of research in the field.

\section{Data sharing}

Extra data and information is available by emailing to nhliza@hotmail.com (Attention Dr. Nik H Rahman). Extra data can also be obtained from websites as follows:

a) Ministry of Health Malaysia at http://www.moh.gov. my/images/gallery/stats/heal_fact/health_fact_2012 page_by_page.pdf

b) Ministry of Transport at http://www.jpj.gov.my/web/ eng/statistic

\section{Competing interests}

The authors declare that they have no competing interests.

\section{Authors' contributions}

NHNAR contributed to the manuscript preparation and data collection from other sources. KAB contributed to the reviewing of the manuscript. SMSM contributed to the conception and framework of the manuscript. All authors read and approved the final manuscript.

\section{Acknowledgments}

We acknowledge the financial support from a Research University (RUI) grant (1001/PPSP/812099) for the pilot project of the electronic road traffic injury surveillance (eRTIs) development in the Universiti Sains Malaysia.

Author details

${ }^{1}$ School of Medical Sciences, USM, Kota Bharu 16150, Malaysia. ${ }^{2}$ School of Health Science, USM, Kota Bharu 16150, Malaysia.

Received: 26 November 2014 Accepted: 20 May 2015

Published online: 04 June 2015

\section{References}

1. Malaysia National Statistical Office. The statistic handbook of Malaysia 2012 Available at https://www.statistics.gov.my/ (accessed 10th June 2015).

2. WHO. Countries database. 2011 Available at http://www.who.int/countries/ mys/en/ (accessed 20th December 2013).

3. Malaysia Ministry of Health. Health facts 2012. 2012. Available at http://www.moh.gov.my/ (accessed 20th December 2013). 
4. WHO world report on road traffic injury prevention. Available at http://www.who.int/violence_injury_prevention/publications/road_traffic/ world_report/en/index.html (accessed 20th December 2013).

5. Statistic on road traffic accidents 2012 by Malaysian Police Force. Available at http://trafik.rmp.gov.my/copsportal/ (accessed 10th June 2015).

6. Statistics on road traffic injury by the Road Safety Department Malaysia. Available at http://www.jkjr.gov.my/ms/maklumat_keselamatan/statistik.html (accessed 1st January 2014)

7. Sethi D, Aljunid S, Saperi SB, Clemens F, Hardy P, Elbourne D, et al. Comparison of the effectiveness of trauma services provided by secondary and tertiary hospitals in Malaysia. Ann Emerg Med. 2007;49(1):52-61.

8. Sabariah FJ, Ramesh N, Mahathar AW. National trauma database (NTrD)-improving trauma care: first year report. Med J Malaysia. 2008;63(Suppl C):45-9.

9. Lin MR, Kraus JF. A review of risk factors and patterns of motorcycle injuries. Accident Anal Prev. 2009;41(4):710-22

10. Pang TY, Umar RS, Azhar AA, Ahmad MM, Nasir MT, Harwant S. Accident characteristics of injured motorcyclists in Malaysia. Med J Malaysia. 2000;55(1):45-50

11. Official website of Malaysian Institute of Road safety Research. Available at http://www.miros.gov.my/web/guest/home (Accessed 6th January 2014).

12. Official website of Department of Road safety Malaysia (JKJR). Available at http://www.jkj.gov.my/ms/ (Accessed 6th January 2014).

13. Radin Umar RS. Motorcycle safety program in Malaysia: how effective are they? J Injury Control Safety Promot. 2006;13(2):71-9. Taylor \& Francis.

14. Radin URS, Mackay MG, Hills BL. Modelling of conspicuity-related motorcycle accidents in Seremban and Shah Alam, Malaysia. Accident Analy Prev. 1996;28(3):325-32.

15. Wells S, Mullin B, Norton R, Langley J, Connor J, Lay-Yee R, et al. Motorcycle rider conspicuity and crash related injury: case-control study. BMJ (Clinical Research Ed). 2004;328(7444):857.

16. Official website of Malaysian Institute of Road safety Research. Standards \& Industrial Research Institute of Malaysia (SIRIM). Available at http://www.sirim.my/. (Accessed 12th January 2014)

17. Ambak K, Riza Atiq A, Rozmi I. Intelligent transports system for motorcycle safety and issues. Eur J Sci Res. 2009;28(4):600-11.

18. Law TH, Lin XU, Radin Umar RS. Factors influencing red light runners among motorcyclists in Malaysia. Available at http://www.miros.gov.my/ web/guest/publications?p_p_id=101_instance_ceit\&p_p_lifecycle $=0 \&$ $p \_p \_$state $=$normal $\& p \_p$ mode $=v i e w \& p \_p \_c o l i d=r i g h t b a r \& p \_p$ col_pos=1\&p_p_col_count $=2 \&$ _101_instance_ceit_struts_action $=\%$

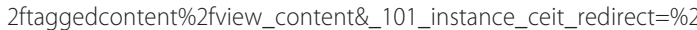
fweb\%2fguest\%2fpublications\&_101_instance_ceit_assetid=25428. (accessed 12th January 2014)

19. Ooi SS, Wong SV, Radin Umar RS, Azhar AA, Megat Ahmad MMH. Cervical spine injuries sustained by motorcyclists in Malaysia. Available at http:// www.miros.gov.my/web/guest/publications?p_p_id=101_instance_ceit\& p_p_lifecycle $=0 \& p \_p \_s t a t e=$ normal $\&$ p_p_mode $=$ view\&p_p_col_id $=$ rightbar \&p_p_col_pos=1\&p_p_col_count $=2 \&$ _101_instance_ceit_struts_action $=\%$ 2ftagged_content $\% 2 f v i e w \_c o n t e n t \&$ 101_instance_ceit_redirect $=\%$ 2fweb\%2fquest\%2fpublications\&_101_instance_ceit_assetid=25361. (accessed 12th January 2014)

\section{Submit your manuscript to a SpringerOpen ${ }^{\circ}$ journal and benefit from:}

- Convenient online submission

- Rigorous peer review

- Immediate publication on acceptance

Open access: articles freely available online

- High visibility within the field

- Retaining the copyright to your article

Submit your next manuscript at $>$ springeropen.com 